\title{
Shared Mental Models in Creative Virtual Teamwork
}

\author{
Beke Redlich $^{1}$, Dominik Siemon ${ }^{2}$, Christoph Lattemann ${ }^{1}$, Susanne Robra-Bissantz ${ }^{2}$ \\ ${ }^{1}$ Jacobs University gGmbH $\quad{ }^{2}$ University of Braunschweig \\ $\{$ b.redlich|c.lattemann\}@,jacobs-university.de, \{d.siemon|s.robra-bissantz\}@,tu-braunschweig.de
}

\begin{abstract}
This paper presents an experiment on the impact of Shared Mental Models (SMM) on creative virtual teamwork. We tested whether the usage of an online whiteboard influences the building of SMM in the initial phase of virtual teamwork. As SMM are the foundation for successful collaboration in teams, we transferred the construct on measuring the team task and team goal in a creative virtual team process. In the first section of the paper a theoretical discussion on $S M M$, creativity and virtual teamwork will be presented. Subsequently, our experiment on virtual teamwork via the use of a virtual tool and its impact towards SMM will be introduced and the results will be discussed. We identified that specific creative competencies of virtual tools enhance the level of SMM but still lack in perceived efficiency compared to physically present teamwork. The findings recommend further research on the applicability, effectiveness and capabilities of creative virtual tools.
\end{abstract}

\section{Introduction}

Fostering creativity, developing innovative products and services as well as solving complex tasks are current challenges in daily business life. Various creative innovation approaches, such as Design Thinking, have been developed in the past decades to provide a method to solve these challenges. A fundamental element of these methods is teamwork in diverse working areas.

Within changing business environments due to technological achievements, teamwork can be performed time- and location-independent on a virtual level by the use of Information and Communication Technology (ICT). Virtual Teams are confronted with different challenges than face-to-face teams concerning for instance the remote understanding of the overall task that has to be solved.

Past research has shown that Shared Mental Models (SMM), on a face-to-face level, are crucial for the success of a team [33]. SMM relate to a collective comprehension between all individuals in a team concerning several aspects of teamwork such as tasks, goals and skills [33,34]. In this paper, we will discuss the impact on SMM within virtualized collaboration.

Transferring and analyzing the results in research already conducted in the area of SMM, creativity and virtual teams, we aim to initialize a scientific discussion on the building of SMM in virtual team environment concerning the use of visualization. Namely, we test the influence of and on SMM when using a virtual visualization tool as a teamwork facilitator. With our conducted experiment, we identified that virtual teams, using visualization tools, work more effective and satisfied and can build a higher shared understanding.

In the first section of this paper a theoretical foundation of SMM and virtual teams will be presented and discussed in the context of using ICT that supports the visualization of a SMM. Following, the assumptions and hypotheses will be presented and the research experiment will be introduced.

In the second section the methodological approach of the experiment will be described in detail and the results will be presented subsequently. The third and closing section of this paper discusses the experiment's results followed by the conclusion.

\section{Context}

This study is part of a larger project in which we analyze the effects on and the chances of SMM in a virtual Design Thinking process. Design Thinking is inherently based on teamwork and comprises creativity, multidisciplinarity, collaboration, cocreation and iteration. Design Thinking uses tools in a sequence, borrowed from different scientific disciplines like social sciences (e.g. psychology and economics), design sciences (e.g. architecture) and engineering (e.g. computer sciences, mechanical engineering). In the past years various tools were developed as a digitized version and are offered online (e.g. www.mural.co). There is a high number of virtual tools with a vast variety of functionalities and application areas. Despite the vast presence and use of online tools, which may support a Virtual Design 
Thinking process, there is no complete reproduction of a whole face-to-face Design Thinking process available yet. Well-developed, scientific-based approaches for "Virtual Design Thinking" are missing.

Our motivation for this paper comes from a Design Thinking perspective, which explains several aspects included in our paper, e.g. the debate on Wicked Problems in a virtual creative teamwork. Nonetheless, we firstly focus on the role of SMM in creative virtual teams.

\section{Shared Mental Models}

Shared Mental Models (SMM) are psychological constructs and describe the accumulation of diverse Mental Models represented in a team. Each individual has made up a Mental Model in order to synthesize the diverse facets a person acts in. Mental Models are defined as individual cognitive displays relating to one's specific structures as foundation for interaction $[29,31]$. On the one hand, a Mental Model helps to explain individual's decision making. On the other hand, the understanding of Mental Models reveals the needs of individuals to perform in specific situations.

Whereas Mental Models refer to the individual level of humans, the concept was transferred to a team level - the accumulation of different Mental Models represented in a group. The so called Team Mental Model reveals a common comprehension between individuals in a team concerning specific facets on occupational concerns such as task, performance and interaction [7,8,29,31]. One focus of Team Mental Models are resemblances of Mental Models - Shared Mental Models [7,8,26,29]. SMM in research have been theorized with different foci whereas the emphasis has developed strongly towards the joint comprehension shared by all members in a team while different Mental Models are existent [19,25,33]. This refers to the congruent development of SMM that is needed for successful collaboration [19,22]. Furthermore, SMM embody knowledge structures that unite individuals in a team [34]. The shared structures of SMM lay open a path on how individuals may perform as a team in their surrounding [34]. de Vreede et al. (2012) collated the following structures of SMM that are split into four categories: Firstly, knowledge structures on equipment and tools; secondly, team task, goal, and performance requirements; thirdly, knowledge about other team members' abilities, knowledge, and skills and fourthly, knowledge about appropriate team interactions [34]. Past research often focused on one of the above mentioned categories [34]. Moreover, the purpose of SMM are to enable the members of one team to build upon their own knowledge structures as a pathway finder on interaction with team members as well as forecast on knowing how to process as a team [24].

\subsection{Shared Mental Models and Creativity}

One major aspect in SMM research is the relation between SMM and creativity. The ability of being creative in a team is defined as generating novel ideas, which lead to innovative products and services as well as processes in order to reach the organization's objectives in an improved manner [2,6,33]. This also resembles the idea of innovation methods such as Design Thinking. Within SMM research a debate on whether SMM foster or tackle creativity has been discussed over the past years [33]. Scholars who assume a negative effect of SMM on creativity claim that a high proportion of SMM hinder creativity. This is because over a longer period of time the harmonization of SMM leads to a comfortable position that is barely risked [6]. The situation of high SMM in teams could lead to avoidance of conflict which is related to a restriction in solution space that might hinder creative and innovative results $[6,33]$. It has to be outlined that the argumentation is connected to the lifespan of a team. Meeting in always changing team constellation might turn the described effects. The study of Santos et al. (2015) states that empirical research on the influence of SMM on creativity is still missing but their own study did a convincing contribution in presenting that SMM "positively influences team creativity, and in turn team effectiveness." [33, p. 653]. It has been determined that the SMM categories such as team processes, communication patterns and task orientation have a positive effect on creativity [33]. Likewise, Santos et al. (2015) concluded that SMM in a team leads to generating new ideas transferred onto new products (or services) which suit the demands and necessities of task and team [33]. Accordingly, teamwork supported by SMM result in satisfaction of the individual and convincing standard of enactment [33]. Scholars who claim that SMM have a positive effect on creativity state that the ability of adaptation either on sharing Mental Models or being commonly creative resemble each other as both aspects solve problems [6,33]. Accordingly, SMM represent the team member's ability to foreshadow the desires and activities of team colleagues in order to familiarize and by that perform interactions that are positive for teamwork, -processes, -tasks and -goals [8,33]. The following section will describe the relationship between SMM, creativity and virtual teams. 


\subsection{On Teamwork, Virtual Teams and Shared Mental Models}

Teamwork has become an integral part of daily business life that cannot protect itself from changing business environments: Originally teamwork was based on the physical presence of team members but since the enhancement of ICT, teamwork can be performed location-independent on a virtual level [25]. Maynard and Gilson (2013) go even a step further in stating that “today's teams rely extensively, and sometimes even exclusively, on technology to communicate" $[25$, p. 2]. This development might even increase since the quality, competencies and variety of ICT will probably rise, and this is indispensably connected to changes in working structures. Existing research on the impact of ICT on teamwork is limited but current studies show that the application of ICT in team contexts can either result in positive, negative or neutral effects on team performance [25].

Teamwork in general implies three major aspects such as working interdependently with other members, incorporating the ability to adapt to demands of team members and team task, dynamic communication as well as information transfer and adapting towards a certain lifespan of a task that has to be solved commonly [32]. Teamwork is part of diverse occupations and can even be performed without the physical presence of team members, hence in virtual teams. Virtual teams have been defined as teamwork that is based on technology-mediated communication while crossing several boundaries [18] and rely on a certain degree of the usage of virtual tools in order to organize and perform a team process [25].

Due to the advanced settings of virtual teams in comparison to face-to-face teams particular challenges influence the functioning of virtual teams. Maynard and Gilson (2013) determine that the common comprehension of a team task developed via SMM is a prerequisite for successive team performance, no matter what kind of communication is chosen [25]. Working virtually in a team implies an advanced challenge for each team member due to time and timing aspects. On the one hand, when using virtual tools the current person in charge has to comprehend what the person/people did previously and what can be done now in the context of the overall team task time-independence relates to task interdependency [25]. On the other hand, virtual teams might foster simultaneous collaboration that needs to be organized in terms of time and timespan.

\subsubsection{Shared Mental Models in Virtual Teams}

Until now most research has focused on building SMM and their effects on given aspects in physically present teams but there is still a lack in research on SMM in virtual teams [25]. However, the findings already made will be used as a basis for our paper. Within the research on the role of SMM in virtual teams, Maynard and Gilson (2013) investigated the effects of technology used by virtual teams on SMM, more specifically on the SMM knowledge structures team and task. They found out that the proposed SMM knowledge structures can be similarly treated in faceto-face teams and virtual teams, as both need to have a common comprehension of what to do (task) and how to organize their activity (process) [25]. Furthermore, the authors identified that technology used by virtual teams can either impede or support the building of SMM. This is due to the fact that SMM are built in phases, which is influenced by the choice and use of virtual tools/technology in virtual team processes [25]. Accordingly, the choice of virtual tools concerning their competencies has a tremendous effect on SMM [25]. These findings lead to our assumption that a further examination on specific virtual tools and their role towards SMM needs to be conducted. The foundation for building SMM in virtual teams is appropriate communication that facilitates a shared task comprehension as starting point for a common team process [24].

\subsection{Wicked Problems, Visualization and Shared Mental Models}

Buchanan (1992) presented a paper on "Wicked Problems in Design Thinking" in which he outlined that problems, which are indefinite and with no way towards fast solution can appropriately be solved in the way designer think, hence with Design Thinking, which can be transferred on a general creative approach to solving Wicked Problems [15]. Although slightly different in definition, the so called Complex Problems have already been identified in SMM research. In the past decades research on Complex Problem Solving (CPS) has been established within the area of psychology [13]. A CPS is defined as process where a sequence of tasks are needed to come to a result - challenges are: complexity (several requirements influence clarification), connectivity (interconnectivity of events and aspects), dynamics (changing events and requirements) and no transparency (the given events are not predictable) 
$[11,13]$. When teams are confronted with Complex Problems, the establishment of SMM is advantageous, as the ability on adaptation is highly demanded in this context. Since past research has shown that SMM, more specifically the ability towards adaptation, have a positive effect on solving Complex Problems, we propose that SMM also have a positive effect in solving Wicked Problems. This proposition refers to the similar interdependent structure of both Complexand Wicked Problems and that the competence of adaptation within a team remains the same challenge in both processes.

One way to achieve SMM in Wicked Problem environment is visualization. Visualization is used in multiple occasions to facilitate creative teamwork. Various research already examined the usage of visualization tools as structural support for individual or collaborative knowledge construction. Visualization can be effectively used to represent individual opinions in order to support reasoning. Visualizing a Mental Model can therefore help to express complex thoughts [12]. Findings show that especially in an early stage of a problem-solving task, the process and the outcome can be improved by providing people with the possibility to visualize their thoughts [3,12]. Using visualization to enhance SMM has been identified as a suitable approach to support collaborative learning, negation and decision making as well as to promote group consensus $[21,30]$. In collaborative visualization, the visual representation of individual mental models is challenging. Due to different opinions, cultures, background, interests and paradigms [21], the building of SMM can cause problems in communication and cooperation, which can result in a ineffective team performance $[20,21,24]$. This requires a suitable tool to head towards a visual representation of a SMM. We focus on the measurement of the effects of visualization and especially of virtual collaborative visualization of a Wicked Problem on SMM. We additionally aim to measure the effectiveness and satisfaction level of a virtual visualization tool used in a collaborative process to identify novel and effective types of ICT to support this process.

Yusoff and Salim (2015) identified five types of visualization on a virtual team level: shared - and shared coordination visualization, shared multiple representation and shared mirroring display - each type has effects on SMM [37]. Shared visualization is utilized to envision content, process and artifacts within a team process in order to foster SMM [37]. The visualization type shared mirroring display supports collaboration within interrelated tasks whereas shared multiple representation collates different visualizations for collaboration, which can be advantageous for solving Wicked Problems. All of these categories refer to different kinds of visualization concerning methodology, collaboration, complexity, etc. Yusoff and Salim (2015) examined the type of visualization concerning competencies of specific technologies [37], our focus is the investigation of the effect on SMM when using virtual visualization in teams.

\section{Methodology}

The description and discussion of theoretical backgrounds, common roots and relation between SMM, creativity and virtual teams show a common ground for research on specific virtual tools to further investigate and improve creative virtual teamwork.

In this paper, we test the impact of the use of a virtual tool, in particular visualization, on SMM in teamwork. With this research aim, we follow the suggestion from Maynard and Gilson (2013) who proposed that research on SMM in virtual teams would outline the effects of individual reaction on different technologies and help to explore the application of innovative IT and its effect on SMM and enactment of virtual teams [25].

As starting point to our research aim, we begin to test how SMM can be ideally build in virtual teams in the initial phase of creative teamwork. We analyze, if visualization can improve a shared understanding of a given problem in virtual teams.

We set up an experiment to examine the usage of a virtual tool that supports the interactive and collaborative building of a visual representation of a given problem [9,17,27].

Our objectives are to answer the following research questions:

(1) How do individuals adapt given technologies to fit their needs [25]?

(2) What novel types of ICT can be used to enhance the development of SMM and support virtual team performance?

For a comprehensive analysis we thus evaluate if our chosen virtual tool provides an effective way of dealing with a Wicked Problem, as well as the level of satisfaction and the way, how the interaction was structured. As teams, "which members structure and organize their team related knowledge" [22, p. 413] tend to easily coordinate their activities and thus improve their team performance, we additionally assess the effectiveness of the virtual tool and the structure of their interaction $[22,23]$. We derive the following three hypotheses to evaluate the effects of our proposed virtual tool. A virtual visualization tool that offers a variety of visualization features, bears

(H1) a higher level of shared understanding of a team task and a team goal ... 
(H2) a higher level of satisfaction ...

(H3) a higher level of perceived effectiveness ...

(H4) a more structured team interaction ...

... in comparison to a system without the functionality of visualization.

In order to validate our hypotheses, we conducted an experiment with two groups that used different virtual tools. Our experimental group used an online whiteboard - originally designed to support Design Thinking - called Spacedeck (www.spacedeck.net). Spacedeck is a virtual collaboration tool for visualization, with specific competencies such as the possibility to draw or insert text, forms and multimedia like audio-, video- and image files. The whiteboard has an intuitive functionality and its collaboration can be performed in real-time with multiple geographically dispersed users. Additionally, a chat function supports communication within virtual teams. Spacedeck has been developed to support especially creative work in creative projects and enterprises for visual collaboration.

Whiteboards play an important role in creative teamwork processes since its plain surface is used for visualization of tasks, ideas, images and other methods. In physically present teams a whiteboard is a support to visualize while communication proceeds and nonverbal signs influence the interaction $[14,36]$. For that reason, we chose the online Whiteboard Spacedeck since its functionalities come close to a physically present environment. In contrast, the control group used a simple chat system without having the possibility to visualize their thoughts.

\subsection{Experiment structure}

We conducted an experiment with 40 participants, which involved undergraduate and graduate students in the ages between 22 and 30 . The participants were students with majors in the fields of computer science, technology-oriented business administration, engineering and other technological studies. In the beginning, the participants were randomly and blindly assigned to either an experimental (EG) or control group (CG). We included a total of 10 teams (5 experimental teams, 5 control teams) with 4 team members each, as larger team sizes are less likely to build SMM [4]. Overall, we had 34 male and 6 female participants. Both groups were assigned to collaboratively engage with the same given task. For the purpose of the experiment, we used a Wicked Problem that all team members should commonly understand in order to be able to formulate a team process. Wicked problems have a high number of elements that are relevant to the solution process and are interconnected. Wicked Problem solutions can be evaluated as good or bad but there is no right or wrong, there is no similar approach to solution adapted from other problem solving processes, there are several explanations due to ideology, Wicked Problems are dependent to other (complex) problems, there is just one chance for success and no failure allowed $[5,13]$. For our experiment we used the Wicked Problem of radioactive waste, including its origin and handling. The problem of nuclear waste is a commonly known issue, frequently discussed in the media with many views and concerns. Our defined problem contained 28 elements like nuclear fission, uranium mining, tailing, nuclear medicine, nuclear reprocessing and interim storage. The problem had no definite formulation, had no stopping rule, had a highly nontransparent structure with a variety of connections, influences, different possible goals and confusing information [5,13]. However, the structure and relations between each element (e.g. "uranium mining leads to tailing") was explained in a textual description.

Both groups had the same textual description of the problem, whereat the experimental group used the online-whiteboard tool to be able to further visualize the problem. Both groups were given a chat function that should be used for communication within the teams. The teams had 20 minutes to collaboratively deal with the problem by using the given functions. Experiments with test groups, prior to the experiment, showed that the participants tended to finish working on the wicked problem after about 20 minutes. Hence, we determined a 20-minute timeframe for the group work. Additionally, no participant in our experiments asked for additional time. Both groups had the same instructions: first, deal with, and understand the problem; second, find a common goal and reach agreement. The teams were not asked to produce ideas at this very beginning of a teamwork process. Both groups were introduced to the tools four days in advance, to get familiar with the functionality. After the process, each team member received a survey to individually rate the level of SMM, perceived effectiveness, satisfaction and the way the team interacted. On the one hand, these questions provide us feedback on the effect on SMM when the support of visualization in virtual teams is given. On the other hand, by evaluating the survey we can outline whether visualization in virtual teamwork is able to keep up in terms of perceived effectiveness, satisfaction and interaction in comparison to physically present teamwork. Both, the survey and the experiment data will provide us indication on first, the effect on SMM within the experiment structure and second, whether the chosen virtual visualization tool can appropriately serve as replacement for physically present teamwork in the initialization phase of a creative teamwork. 


\subsection{Measures}

To validate our hypotheses, we disposed four dependent measures. Our measure, shared understanding of team task and goals, contains 21 unweighted items from Johnson et al. (2007) and Santos et al. (2015), that are rated on a 5-point Likertscale [16,33]. Our second measure, satisfaction, evaluates the level of satisfaction of the participants with the tool. It contains 7 unweighted items from Dennis et al. (2006) and Santos et al. (2015) and is rated on a 5-point Likert-scale [10,33]. The third measure involves the perceived effectiveness of the process and contains four unweighted items, rated on a 5-point Likert-scale. The last measure, structured interaction, evaluates, how well structured and goal oriented the discussion was and how the communication in the team was perceived. The measure contains five unweighted items from Alrushiedat \& Olfman (2012), and van der Pol et al. (2006), with different rating scales [1,28]. Table 1 shows the measures, which were captured in a postprocess survey.

\begin{tabular}{|c|c|c|}
\hline Measure & Items & Scale range \\
\hline $\begin{array}{l}\text { Shared } \\
\text { understanding of } \\
\text { the team task and } \\
\text { goal }\end{array}$ & 21 & $\begin{array}{l}\text { 1=Strongly } \\
\text { Agree; } \\
\text { 2=Agree; } \\
\text { 3=Undecided; } \\
\text { 4=Disagree; } \\
\text { 5=Strongly } \\
\text { Disagree }\end{array}$ \\
\hline Satisfaction & 7 & $\begin{array}{l}\text { 1=Very satisfied; } \\
2=\text { =Satisfied } \\
3=\text { Neither; } \\
\text { 4=Dissatisfied; } \\
\text { 5=Very } \\
\text { dissatisfied }\end{array}$ \\
\hline $\begin{array}{l}\text { Perceived } \\
\text { effectiveness }\end{array}$ & $3+1^{1}$ & $\begin{array}{l}\text { 1=Very effective; } \\
\text { 2=Effective; } \\
3=\text { Neither; } \\
\text { 4=Ineffective; } \\
\text { 5=Very } \\
\text { ineffective }\end{array}$ \\
\hline $\begin{array}{l}\text { Structured } \\
\text { interaction }\end{array}$ & $3+2^{2}$ & $\begin{array}{l}\text { 1=Strongly } \\
\text { Agree; } \\
\text { 2=Agree; } \\
\text { 3=Undecided; } \\
\text { 4=Disagree; } \\
\text { 5=Strongly } \\
\text { Disagree }\end{array}$ \\
\hline
\end{tabular}

Table 1: Measures

1 The item "How effective was this meeting compared to a face-to-face meeting." is excluded from the mean and t-test calculations.
${ }^{2}$ The measure structured interaction contains two questions, which are excluded from the mean and t-test calculations due to an inverted scale and a neutral loading: Question 1: "The discussion was factual, not personal nor critical." and question 2: "Many explanations were necessary during the process."

In addition, we capture the whole communication process of each team. We further compute the mean of the number of words used for communication to find out if SMM need intensive direct communication or if SMM can be built on a mix of communication and visualizing of the given Wicked Problem.

\subsection{Results}

The survey resulted in overall 1480 ratings by 40 participants. We calculated the means and standard deviations of every measure and computed a set of two sample t-tests to validate our hypotheses. Table 2 shows the results of the experiment.

\begin{tabular}{|l|l|l|}
\hline Measure & Means & SDs \\
\hline $\begin{array}{l}\text { Shared } \\
\text { understanding of } \\
\text { the team task and } \\
\text { goal }\end{array}$ & $\overline{\mathrm{X}}_{\mathrm{EG}}=1.919$ & $\overline{\mathrm{X}}_{\mathrm{EG}}=.837$ \\
\hline Satisfaction & $\overline{\mathrm{X}}_{\mathrm{EG}}=3.548$ & $\sigma_{\mathrm{CG}}=.940$ \\
\hline $\begin{array}{l}\text { Perceived } \\
\text { effectiveness }\end{array}$ & $\overline{\mathrm{X}}_{\mathrm{CG}}=3.436$ & $\sigma_{\mathrm{EG}}=.916$ \\
\hline $\begin{array}{l}\text { Structured } \\
\text { interaction }\end{array}$ & $\overline{\mathrm{X}}_{\mathrm{EG}}=2.233$ & $\sigma_{\mathrm{CG}}=.969$ \\
\hline
\end{tabular}

Table 2: Results; (experimental group: EG; control group: $\mathrm{CG}$ )

The two sample t-tests validate our hypotheses. Shared understanding of the team task and goal is significantly higher in the experimental group (mean=1.919) than in the control group (mean=3.548, $\mathrm{t}=25.527, \quad \mathrm{p}=2.2 \mathrm{e}-16, \quad \mathrm{df}=838)$. Satisfaction is significantly higher in the experimental group $(m e a n=2.050)$ than in the control group (mean $=3.436$, $\mathrm{t}=12.298, \mathrm{p}=2.2 \mathrm{e}-16, \mathrm{df}=278$ ). Perceived effectiveness is significantly higher in the experimental group $($ mean $=2.233)$ than in the control group (mean $=3.700$, $\mathrm{t}=10.796, \quad \mathrm{p}=2.2 \mathrm{e}-16, \quad \mathrm{df}=118)$ and structured interaction is significantly higher in the experimental group (mean=1.917) than in the control group (mean $=3.183, \mathrm{t}=7.9633, \mathrm{p}=1.165 \mathrm{e}-12, \mathrm{df}=118$ ).

Both groups stated that the discussion was factual, not personal nor critical $\left(\overline{\mathrm{X}}_{\mathrm{EG}}=1.450 ; \overline{\mathrm{X}}_{\mathrm{CG}}=1.800\right)$, but also stated that many explanations were necessary during the process $\left(\overline{\mathrm{X}}_{\mathrm{EG}}=2.400 ; \overline{\mathrm{X}}_{\mathrm{CG}}=2.250\right)$. Both groups, however, stated that the process was not as effective as a face-to-face meeting $\left(\overline{\mathrm{X}}_{\mathrm{EG}}=3.450\right.$; 
$\left.\overline{\mathrm{X}}_{\mathrm{CG}}=4.000\right)$. The experimental teams used on average 260 words for their group interaction, whereas the control teams used on average 514 words. Every experimental group came up with a comprehensive figure of the Wicked Problem, containing every important element of the problem construct. Figure 1 shows the produced visualization of the Wicked Problem of one experimental team.

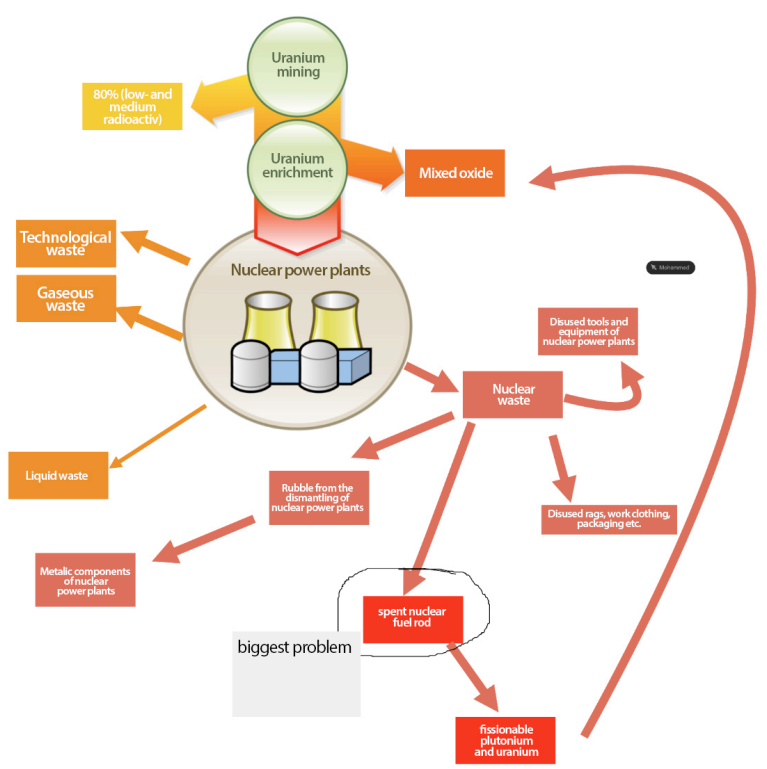

Figure 1: Visualization of the Wicked Problem produced by an experimental team (translated into English)

\section{Discussion}

With our experiment we aimed to evaluate the applicability of an online-whiteboard to build a shared understanding of a team task and a team goal within virtual teams. In addition, we evaluated whether the online-whiteboard offers an appropriate way to collaboratively deal with a given task, whether it supports a more structured interaction and whether it leads to a satisfied usage. Our experimental teams who used the online-whiteboard outperformed the control teams that did not have the functionality of visualizing their thoughts. The experimental group had a significant higher shared understanding of the team task and team goal, a higher perceived effectiveness, a higher level of satisfaction and a more structured process. The given results present a significantly higher SMM when visualization is used in virtual teamwork. This supports the assumption that SMM work as a proper indicator for creative virtual teamwork. However both groups stated, that using the virtual tool is less effective than a face-to-face teamwork. Face-to-face situations offer several more possibilities for communication, interaction, and knowledge sharing in comparison to the limited competencies of our web-based virtual tool [35]. Even though, we identified a significant difference between two virtual tools, we did not intend to establish a virtual tool to outperform face-to-face meetings. In fact, the results show that a virtual tool can even impede SMM as already mentioned by Maynard and Gilson (2013).The teams of the control group used on average more words during their discussion. This is due to the fact, that they needed more words to describe the problem, as there was no other way of collaboration like visualization. In addition, they spent more time discussing their procedure, whereas the experimental teams started working faster. Although, both groups reported that many explanations during the experiment were necessary, the qualitative analyses of the chat history showed, that only the control group discussed the interconnections, influences and the structure of the Wicked Problem. Whereas the experimental group mainly discussed the usage of the tool. These findings give answer to our research question how individuals adapt to given technologies to fit their needs. The control teams had only one possibility to collaborate via the use of the chat function - the qualitative evaluation of the chat history outlined that team members concentrated on task relevant communication, which underlines that given technology was adapted towards team task and team goal related needs. In contrast, the experimental group adapted the chat function for team process relevant communication such as the functionality of the tool, since the opportunity to visualize substituted team task and goal oriented chat-communication. But it has to be considered that the small number of participants limits the generalizability of the results. However, our experiment shows that an online-whiteboard offers an appropriate way to build SMM. This is the answer to our second research question, asking what novel types of ICT can be used to enhance the development of SMM and support virtual team performance. Our chosen virtual tool is relatively new and its abilities come close to the abilities of physically present teams (visualization in form of text, images, communication and collaboration).

\section{Conclusion and Outlook}

As customers, business partners, employees and other stakeholder are increasingly dispersed around the globe, creative team processes must be adapted towards a virtual, time- and location-independent process via the support of ICT. We started our research by firstly identifying virtual tools that support the 
development of SMM which are the basis for collaborative work and hence the founding pillar for creativity and innovation methods. By assigning existing virtual tools on their application within a creative process, we decided to focus on the initializing phase. Furthermore, we decided to use an onlinewhiteboard as appropriate virtual tool. The functionality of a (online) whiteboard offers the possibility to start from a plain surface to arrange necessary aspects, questions and interdependencies until a Wicked Problem is appropriately illustrated. This reveals a common understanding of a team task, goal and process via collaboratively visualizing in a virtual team. SMM act as indicator for successive teamwork. This paper shall act as a starting point towards improving creative virtual teamwork via the usage of SMM as proving indicator. To reach the goal of virtually performing creative processes, a multiplicity of aspects such as synergies and visualization competencies need to be protected and technological requirements for creative virtual teamwork need to be aligned and improved according to teamwork processes, e.g. collaboration and usability. Our experiment has shown that virtual visualization of a Wicked Problem increases the level of SMM and its perceived efficiency by members in a virtual team. The combination of SMM, virtual teams, creativity and Wicked Problems revealed a foundation for time- and location-independent teamwork with the help of ICT und thus initializing a first step towards "Virtual Design Thinking”.

The next step in our research is to improve the performance of virtual tools in a way that their use is as efficient as face-to-face teamwork. To increase the quality, efficiency and satisfaction of virtual creative processes, further investigation on the usage of ICT and virtual tools for the initialization phase as well as the following team process phases need to be conducted. We suggest analyzing different types of virtual visualization tools as well as other tools that support creativity to prove their competencies and impact on SMM in a creative teamwork context.

Further on, our experiment focused on the two SMM knowledge structures team task and team goal, for more detailed results other knowledge structures such as knowledge about abilities, competencies and skills of team members could be taken into account via the application of social media profiles. Furthermore, we suggest an experiment environment with diverse cultural backgrounds of participants to investigate the effects of culture and SMM in virtual creative teamwork. Additionally, we suggest the investigation of other creative methods for visualization than whiteboards to enhance team performance.

\section{Acknowledgements}

This paper is part of a project called DETHIS Design Thinking for Industrial Services, funded by the German Federal Ministry of Education and Research (BMBF); Grant \# 01FJ15100.

\section{References}

[1] Alrushiedat, N. and Olfman, L. Anchored Asynchronous Online Discussions: Facilitating Participation and Engagement in a Blended Environment. 2012 45th Hawaii International Conference on System Science (HICSS), (2012), 11-20.

[2] Amabile, T.M. A model of creativity and innovation in organizations. Research in organizational behavior 10, 1 (1988), 123-167.

[3] Blaser, A.D., Sester, M., and Egenhofer, M.J. Visualization in an early stage of the problem-solving process in GIS. Computers \& Geosciences 26, 1 (2000), 57-66.

[4] Bossche, P., Gijselaers, W., Segers, M., Woltjer, G., and Kirschner, P. Team learning: building shared mental models. Instructional Science 39, 3 (2010), 283-301.

[5] Buchanan, R. Wicked Problems in Design Thinking. Design Issues 8, 2 (1992), 5-21.

[6] Burke, C.S., Stagl, K.C., Salas, E., Pierce, L., and Kendall, D. Understanding team adaptation: a conceptual analysis and model. The Journal of Applied Psychology 91, 6 (2006), 1189-1207.

[7] Cannon-Bowers, J.A. and Salas, E. Reflections on shared cognition. Journal of Organizational Behavior 22, 2 (2001), 195-202.

[8] Cannon-Bowers, J.A., Salas, E., and Converse, S. Shared mental models in expert team decision making. Individual and group decision making: Current issues 221, (1993), 221-246.

[9] DeLone, W.H. and McLean, E.R. Information Systems Success: The Quest for the Dependent Variable. Information Systems Research 3, 1 (1992), 60-95. 
[10] Dennis, A.R., Valacich, J.S., Connolly, T., and Wynne, B.E. Process Structuring in Electronic Brainstorming. Information Systems Research 7, 2 (1996), 268-277.

[11] Dörner, D. Vom Umgang mit Unbestimmtheit und Komplexität. Bern: Huber, (1983).

[12] Fischer, F., Bruhn, J., Gräsel, C., and Mandl, H. Fostering collaborative knowledge construction with visualization tools. Learning and Instruction 12, 2 (2002), 213-232.

[13] Funke, J. Complex problem solving: a case for complex cognition? Cognitive Processing 11, 2 (2009), $133-142$.

[14] Hartmann, B., Morris, M.R., Benko, H., and Wilson, A.D. Pictionaire: Supporting Collaborative Design Work by Integrating Physical and Digital Artifacts. Proceedings of the 2010 ACM Conference on Computer Supported Cooperative Work, ACM (2010), 421-424.

[15] Johansson-Sköldberg, U., Woodilla, J., and Çetinkaya, M. Design Thinking: Past, Present and Possible Futures. Creativity and Innovation Management 22, 2 (2013), 121-146.

[16] Johnson, T.E., Lee, Y., Lee, M., O’Connor, D.L., Khalil, M.K., and Huang, X. Measuring Sharedness of Team-Related Knowledge: Design and Validation of a Shared Mental Model Instrument. Human Resource Development International 10, 4 (2007), 437-454.

[17] Keppel, G. Design and analysis: A researcher's handbook (3rd ed.). Prentice-Hall, Inc, Englewood Cliffs, NJ, US, 1991.

[18] Kirkman, B.L. and Mathieu, J.E. The Dimensions and Antecedents of Team Virtuality. Journal of Management 31, 5 (2005), 700-718.

[19] Klimoski, R. and Mohammed, S. Team Mental Model: Construct or Metaphor? Journal of Management 20, 2 (1994), 403-437.

[20] Kolkman, M.J., Kok, M., and van der Veen, A. Mental model mapping as a new tool to analyse the use of information in decision-making in integrated water management. Physics and Chemistry of the Earth, Parts A/B/C 30, 4-5 (2005), 317-332.
[21] Landman, R.B., Broek, E.L. van den, and Gieskes, J.F.B. Creating Shared Mental Models: The Support of Visual Language. In Y. Luo, ed., Cooperative Design, Visualization, and Engineering. Springer Berlin Heidelberg, 2009, 161-168.

[22] Lim, B.-C. and Klein, K.J. Team mental models and team performance: a field study of the effects of team mental model similarity and accuracy. Journal of Organizational Behavior 27, 4 (2006), 403-418.

[23] Link, G.J.P., Siemon, D., Vreede, G.-J. de, and Robra-Bissantz, S. Evaluating Anchored Discussion to Foster Creativity in Online Collaboration. In N. Baloian, Y. Zorian, P. Taslakian and S. Shoukouryan, eds., Collaboration and Technology. Springer International Publishing, 2015, 28-44.

[24] Mathieu, J.E., Heffner, T.S., Goodwin, G.F., Salas, E., and Cannon-Bowers, J.A. The influence of shared mental models on team process and performance. Journal of Applied Psychology 85, 2 (2000), 273-283.

[25] Maynard, M.T. and Gilson, L.L. The Role of Shared Mental Model Development in Understanding Virtual Team Effectiveness. Group \& Organization Management, (2013), 1059601113475361.

[26] Mohammed, S., Klimoski, R., and Rentsch, J.R. The Measurement of Team Mental Models: We Have No Shared Schema. Organizational Research Methods 3, 2 (2000), 123-165.

[27] Nunamaker, J.F., Minder, C., and Purdin, T.D.M. Systems Development in Information Systems Research. Journal of Management Information Systems 7, 3 (1990), 89-106.

[28] van der Pol, J., Admiraal, W., and Simons, P.R.J. The affordance of anchored discussion for the collaborative processing of academic texts. International Journal of Computer-Supported Collaborative Learning 1, 3 (2006), 339-357.

[29] Resick, C.J., Murase, T., Bedwell, W.L., Sanz, E., Jiménez, M., and DeChurch, L.A. Mental model metrics and team adaptability: A multi-facet multimethod examination. Group Dynamics: Theory, Research, and Practice 14, 4 (2010), 332-349. 
[30] Roderick I. Swaab, A.C.M.D. Tom Postmes, Peter Neijens, Marius H. Kiers. Multiparty Negotiation Support: The Role of Visualization's Influence on the Development of Shared Mental Models. Journal of Management Information Systems 19, 1 (2002), 129150.

[31] Rouse, W.B. and Morris, N.M. On looking into the black box: Prospects and limits in the search for mental models. Psychological Bulletin 100, 3 (1986), 349-363.

[32] Salas, E., Burke, C.S., and Cannon-Bowers, J.A. Teamwork: emerging principles. International Journal of Management Reviews 2, 4 (2000), 339-356.

[33] Santos, C.M., Uitdewilligen, S., and Passos, A.M. Why is Your Team More Creative Than Mine? The Influence of Shared Mental Models on Intra-group Conflict, Team Creativity and Effectiveness. Creativity and Innovation Management 24, 4 (2015), 645-658.
[34] de Vreede, T., Boughzala, I., de Vreede, G., and Reiter-Palmon, R. A Model and Exploratory Field Study on Team Creativity. 2012 45th Hawaii International Conference on System Science (HICSS), (2012), 227-236.

[35] Warkentin, M.E., Sayeed, L., and Hightower, R. Virtual Teams versus Face-to-Face Teams: An Exploratory Study of a Web-based Conference System. Decision Sciences 28, 4 (1997), 975-996.

[36] Wood, R. and Ashfield, J. The use of the interactive whiteboard for creative teaching and learning in literacy and mathematics: a case study. British Journal of Educational Technology 39, 1 (2008), 84-96.

[37] Yusoff, N.M. and Salim, S.S. A systematic review of shared visualisation to achieve common ground. Journal of Visual Languages \& Computing 28, (2015), 83-99. 